\title{
Standardisation between livestock classes: the use and misuse of the stock unit system
}

\author{
WARREN J. PARKER \\ Institute of Veterinary, Animal \& Biomedical Sciences, Massey University, Palmerston North ${ }^{1}$
}

\begin{abstract}
The stock unit (SU) system is used extensively in New Zealand agriculture. These applications include inter- and intra-farm comparisons, rural lending and valuation, and farm system design and analysis. The livestock classes and performance levels to which SU conversion factors are applied has increased significantly since Professor Coop defined the ewe equivalent (EE) system, and now includes deer, goats and other non-conventional livestock species. This has led to a proliferation of SU values and their incorrect application and interpretation, especially in between-farm comparative analysis. Benchmarking provides a more economically rational way of improving the profitability of livestock farms than the use of standards based on SUs. Obtaining agreement on the specifications of animal-pasture-financial models to allow users to derive substitution rates between stock classes according to their farm's resources and management practice is preferred to publishing national standards for SUs.
\end{abstract}

Keywords: comparative analysis, livestock classes, standardisation, stock unit

\section{Introduction}

The stock unit (SU) system is used extensively in New Zealand agriculture and its associated service industries. These applications include inter- and intra-farm comparisons (Fitzharris 1982; Baker 1993), rural lending and valuation (Valuation New Zealand (VNZ) sixmonthly reports), farm monitoring and policy advice (MAFPol 1994), enterprise analysis by gross margins (Fleming \& Burtt 1991) and farm system design and analysis (e.g., Keeling et al. 1991). The range of livestock classes to which SU conversion factors are applied has increased significantly since Coop (1965) defined the ewe equivalent (EE) system, and now includes deer and goats (Donaldson 1987), and other non-conventional livestock species. In addition, the range of productive performance within the original sheep categories has changed substantially, and this perhaps, more than the greater diversity of livestock species, has led to a proliferation of SU values and inconsistencies between end-users in their application and interpretation (Crawford \& Anderson 1994). Not surprisingly, SUs have become a point of debate amongst farmers and in the rural service sector.

This paper considers the standardisation of the SU system by: reviewing its development, describing the modifications made for greater liveweight ranges and productive performance, and outlining the economic principles behind standardisation. Limitations of the SU system and the potential to resolve these are discussed.

\section{Evolution of the system in New Zealand}

Crawford \& Anderson (1994) reviewed the history of livestock standards and the SU system in New Zealand. In brief, the SU concept was first reported by Fawcett \& Patton (1929) as a means to assess economic performance in agriculture. Some 30 years later Hutton (1954) defined SUs for measuring the carrying capacity of farms in Waipa County (Table 1). Jackson (1963) subsequently used these standardisation factors to assess the productivity of different pastoral areas in New Zealand. The major breakthrough occurred in 1965 when Coop defined the "standard ewe" upon which the SU system is based as:

... $54.4 \mathrm{~kg}$ in the autumn at mating and gains weight by $2.3 \mathrm{~kg}$ per annum .... It enters the breeding flock as a $45.3 \mathrm{~kg}$ two tooth and leaves it as a 59 $\mathrm{kg}$ ewe some six years later. The mean flock lambing percentage is taken as $100 \%$, so this ewe will have a single lamb, which will be weaned at $22.7-27.2 \mathrm{~kg}$ liveweight at 3.5 months of age. The ewe's lactation will be $113 \mathrm{~kg}$ milk ... It will be shorn once in summer.

This ewe consumed $815 \mathrm{lb}$ pasture of $62 \%$ DOM (approx. $595 \mathrm{~kg} \mathrm{DM}$ ) per year, based on feed requirements published at that time. These were derived mainly from indoor trials, with notional adjustments for

1. Current address: Dairy \& Beef Division, AgResearch, Private Bag 3123, Hamilton. 
comprise 1452 (55 kg, 140\% lambing); 1245 (65 kg, $160 \%$ lambing), or 1097 (75 kg, 180\% lambing) ewes. The extra value per $\mathrm{kg}$ while reducing ewe liveweight from 55 to $45 \mathrm{~kg}$ and maintaining 100\% lambing was $\$ 7.40$, whereas increasing lambs tailed from 100 to $120 \%$ with $55 \mathrm{~kg}$ ewes generated $\$ 5.55$ per $1 \%$ change in lambing. Thus, between farm comparisons based on SUs (or kg liveweight/ha) do not adequately show the economic effects of varying ewe liveweight and prolificacy. Similarly, Crawford \& Lowe (1994) queried the suitability of the SU system for comparing the profitability of beef cattle policies, especially in terms of the higher marginal cost of winter versus spring pasture.

Table 2 Stock unit conversion factors derived from a spreadsheet feed requirements model for ewes of different liveweight and prolificacy (Number of lambs tailed to ewes mated; NLT/EM). The seasonal feed requirements relative to winter are shown for a sub-set of the ewe size prolificacy data (Source: Garrick 1994).

\begin{tabular}{lccccc}
\hline & & \multicolumn{4}{c}{ Ewe liveweight } \\
& & $\mathbf{4 5}$ & $\mathbf{5 5}$ & $\mathbf{6 5}$ & $\mathbf{7 5}$ \\
\hline \multirow{4}{*}{ Prolificacy } & $\mathbf{1 0 0}$ & 0.82 & 0.93 & 1.03 & 1.14 \\
NLT/EM(\%) & $\mathbf{1 2 0}$ & 0.86 & 0.98 & 1.08 & 1.19 \\
& $\mathbf{1 4 0}$ & 0.90 & 1.02 & 1.13 & 1.24 \\
& $\mathbf{1 6 0}$ & 0.94 & 1.06 & 1.17 & 1.28 \\
& $\mathbf{1 8 0}$ & 1.02 & 1.10 & 1.22 & 1.33 \\
& $\mathbf{2 0 0}$ & 1.06 & 1.19 & 1.26 & 1.37 \\
Spring & $\mathbf{1 0 0}$ & 1.29 & 1.22 & 1.17 & 1.42 \\
& $\mathbf{1 2 0}$ & 1.32 & 1.24 & 1.19 & 1.13 \\
& $\mathbf{1 4 0}$ & 1.35 & 1.26 & 1.21 & 1.16 \\
& $\mathbf{1 6 0}$ & 1.38 & 1.29 & 1.23 & 1.17 \\
Summer & $\mathbf{1 0 0}$ & 0.79 & 0.78 & 0.77 & 0.76 \\
& $\mathbf{1 2 0}$ & 0.74 & 0.73 & 0.72 & 0.72 \\
& $\mathbf{1 4 0}$ & 0.70 & 0.69 & 0.69 & 0.68 \\
& $\mathbf{1 6 0}$ & 0.67 & 0.66 & 0.65 & 0.65 \\
Autumn & $\mathbf{1 0 0}$ & 0.72 & 0.73 & 0.73 & 0.73 \\
& $\mathbf{1 2 0}$ & 0.68 & 0.69 & 0.69 & 0.70 \\
& $\mathbf{1 4 0}$ & 0.65 & 0.65 & 0.66 & 0.76 \\
& $\mathbf{1 6 0}$ & 0.62 & 0.63 & 0.63 & 0.64 \\
\hline
\end{tabular}

Amer \& McEwen (1998) also calculated the number of ewes that a farm could carry of different body size and prolificacy. The feed supply was fixed for all options, but different pasture utilisation rates were applied to sheep classes. Feed requirements were derived from Geenty \& Rattray (1987). Amer \& McEwen's substitution rates relative to a $55 \mathrm{~kg}$ ewe (pre-mating) with $100 \mathrm{lambs}$ tailed/100 ewes mated are shown in Table 3. They commented that their SU values were probably over-estimated for highly prolific flocks because increased losses of triplet and higher multipleborn lambs reduce late spring-early summer feed demand.
Table 3 Estimated SU conversion factors for ewes of different liveweight and prolificacy (derived from Amer \& McEwen 1998).

\begin{tabular}{lcccccc}
\hline & \multicolumn{6}{c}{ Ewe liveweight (kg, pre-mating) } \\
& & $\mathbf{5 5}$ & $\mathbf{6 0}$ & $\mathbf{6 5}$ & $\mathbf{7 0}$ & $\mathbf{7 5}$ \\
\hline & $\mathbf{9 0}$ & 0.94 & 0.97 & & & \\
Prolificacy & $\mathbf{1 0 0}$ & 1.00 & 1.03 & 1.06 & & \\
NLT/EM(\%) & $\mathbf{1 1 0}$ & 1.06 & 1.09 & 1.12 & 1.15 & \\
& $\mathbf{1 2 0}$ & 1.12 & 1.15 & 1.18 & 1.21 & 1.24 \\
& $\mathbf{1 3 0}$ & 1.18 & 1.21 & 1.24 & 1.27 & 1.30 \\
& $\mathbf{1 4 0}$ & & 1.27 & 1.30 & 1.33 & 1.36 \\
& $\mathbf{1 5 0}$ & & & 1.37 & 1.40 & 1.43 \\
\hline
\end{tabular}

Table 4 Stock unit conversion factors estimated from a STOCKPOL analysis of a whole farm system for a Romney $(\mathrm{Rn} \times \mathrm{Rn})$, East Friesian $(\mathrm{EF}) \times \mathrm{Rn}$ crossbred and an East Friesian $(E F \times E F)$ flock on medium to steep lower North Island hill country (Source: RomeroGarcia 1998).

\begin{tabular}{lccc}
\hline & $\mathrm{Rn} \times \mathrm{Rn}$ & $\mathrm{EF} \times \mathrm{Rn}$ & $\mathrm{EF} \times \mathrm{EF}$ \\
\hline Wintering nos. & & & \\
- Ewes & 1455 & 999 & 686 \\
- Ewe hoggets & 455 & 310 & 214 \\
- Rams & 20 & 14 & 9 \\
Lambs weaned (\%) & & & \\
- Ewes & 117 & 138 & 230 \\
- Ewe hoggets & - & 80 & 100 \\
Ewe liveweight (kg) & 52 & 67 & 80 \\
- kg sheep/ha & 283 & 252 & 208 \\
Stock unit (SU) factors & & & \\
- Ewe & 1.00 & 1.25 & 1.54 \\
- Ewe hogget & 0.73 & 1.06 & 1.14 \\
- Ram & 0.88 & 1.01 & 1.12 \\
Pasture production & & & \\
- kg DM year & 6683 & 6452 & 6233 \\
- Utilisation (\%) & 89.6 & 87.9 & 84.6 \\
Wool production (kg/yr) & 8408 & 6048 & 2793 \\
Lambs sold (n) & 1221 & 1392 & 1552 \\
- lamb cwt (kg) & 20.9 & 29.0 & 34.7 \\
\hline
\end{tabular}

Romero-Garcia (1998) used STOCKPOL (Marshall et al. 1991) to derive SU equivalents for a Romney ewe $(\mathrm{Rn} \times \mathrm{Rn})$, a heavy highly prolific ewe breed (e.g., East Friesian, $\mathrm{EF} \times \mathrm{EF})$, and a cross of the two $(\mathrm{EF} \times \mathrm{Rn})$ (Table 4). In constrast to Garrick (1994), this analysis incorporated the whole farm and therefore the interaction between the sheep and cattle (fixed) policies and pasture production. Annual pasture production was $3.5 \%$ and $6.7 \%$ less for the $\mathrm{EF} \times \mathrm{Rn}$ and $\mathrm{EF} \times \mathrm{EF}$ ewe systems than the $\mathrm{Rn} \times \mathrm{Rn}$ option, primarily because of the lax grazing associated with more lambs and fewer ewes during summer and autumn (as shown also in Table 2). In practice, a farmer would probably take steps to improve pasture utilisation as flock prolificacy increased, such as raising the proportion of cattle, or selling more 
lambs store pre-Christmas. The viability of these options could be quantified with STOCKPOL. The important issue here is that direct application of SUs to the breed comparison would not have highlighted their effects on pasture productivity/quality.

\section{Comparative analysis and farm standards}

The SU system is used extensively in comparative analysis to identify farm problems and opportunities (e.g., Baker 1993). The analysis is commonly reported as the "top 10\%' vs. the "rest", or "low" "medium" "high" groups (NZMWBES 1989), and is thus used to indicate areas for farm improvement. Essentially, the comparison of farm systems occurs at two levels: within farm across years (or between plans within a year); and across farms (both within and across years). To facilitate comparisons between enterprises, standards, such as those generated through the application of SUs, have been developed. Standards are the average values for a range of production and financial characteristics, and maybe quoted as actual values (e.g., gross farm income (\$)), ratios (e.g., $\mathrm{kg}$ wool/su) or an index (e.g., UPA, King (1982)). Because resources between farms differ, adjustments to standards for variables such as soil type, rainfall, farm size, topography, and livestock policy are often made (e.g., as in PROFITWATCH (Anonymous 1998)). For within-year comparisons adjustments to status quo inventory levels are also required (Shadbolt 1997). Alternatively, several years' data for each farm helps to smooth the effect of atypical events.

Farm standards are a feature of United Kingdom farm management and this precipitated a lively debate in the early 1960s between agricultural economists and farm management specialists (Candler \& Sargent 1962 vs. Blagburn 1962). The former argued that betweenfarm comparative analysis based on farm standards was not economically rational. This is because each farm's unique production function reflects resource quality and the local environment, as well as the preferences and managerial ability of the owner(s). These factors substantially influence how resources are allocated to production. Consequently, as Candler \& Sargent (1962) demonstrated, differences in the values for farm standards do not necessarily measure technical or economic efficiency, and therefore responding to these "gaps" may lead to erroneous conclusions on how to alter the mix of inputs in order to improve profit. The important information for the individual farmer is, "What is the value of an additional unit of input?" Blagburn (1962) in acknowledging their economic argument, contended that standards were still able to broadly indicate areas for farm improvement. Some 30 years later, Malcolm \& Makeham (1993) reiterated the importance of correctly applying economic principles in agriculture and in doing so, listed "common fallacious beliefs" concerning standards and ratios. This included the false belief that physical productivity ratios are equivalent to economic efficiency, and that “... comparisons of average technical ratios, such as $\mathrm{kg}$ / wool/ha or ... gross margins, or costs per dry sheep equivalent (DSE), between farms are valid and thus performance measures on one farm are useful guides for action for another farm. This is invalid." The SU system has been widely misused in this regard. The adoption of nationally agreed values for SUs is likely to perpetrate this misuse.

\section{Benchmarking and the SU system}

Benchmarking has become popular in the 1990s. The aim of benchmarking is to identify superior management practices and/or technologies and to transfer or adapt these to the case farm(s). To paraphrase Atkinson et al. (1995) benchmarking “... is a [farmer's] search for, and implementation of, the best way to do something as practised on other [farms or relevant industries]". To date its application in pastoral agriculture has essentially been an analogue of comparative analysis. Consequently, its power to change farm profitability largely remains unexploited. The three steps in benchmarking are to: identify examples of potential superior performance (such as through comparative analysis of farm business performance ratios (Shadbolt 1997)); establish whether performance is actually superior and if it is, how this is realised; and transfer, if appropriate, the management techniques/practices to the case farm. The SU system could play a role in the initial identification of superior performance, providing the limitations described earlier on technical and economic efficiency are recognised. Successful benchmarking focuses on farmer learning and the ongoing development of "best management practice" (including how to make more effective and efficient use of technology). Publishing standards of farm performance per SU for a farm discussion group, district or farm type, cannot achieve this outcome because they relate to averages rather than the "best" and they do not, by themselves, define the processes and resources through which outstanding performance is realised.

\section{A modelling approach vs national standards}

Irrespective of the concerns about the misuse of standards, the multiplicity of uses of the SU system poses a challenge in achieving an agreed set of national standards. At an industry or agricultural policy level, average values across farm and animal classes are required; at the intra-farm level, values for specific 
groups of animals are necessary. Rather than publishing tables that cover this large range of animal species and performance levels, a more efficient and consistent approach would be to obtain agreement on, and develop, computer-based algorithmns for modelling animal feed requirements in the context of different farm systems. The Internet would allow nationwide user access. There is already a substantial degree of commonality in models used to estimate sheep (see for example, Tables 2 and 3 ), beef cattle, dairy and deer feed requirements. A modelling approach to SU standardisation enables the user to customise the biological and management parameters to their farm system. Deriving SU equivalents is then a straightforward matter of dividing the intake per stock class by a "standard unit" - say, $550 \mathrm{~kg}$ DM of 10.5 MJ ME/kg DM per annum.

The simplest modelling approach is to mechanistically simulate only the animal demand component of the farming system as described by Brookes et al. (1993). However, because of the interaction between the livestock classes, pasture production and quality, and management (see Table 4), modelling the whole system provides more realistic estimates of animal substitution rates within a farm. While this introduces the challenge of simulating feed flows in pastoral systems, detailed sub-models of pasture production under grazing are available (e.g., STOCKPOL (Marshall et al. 1992)). Even if updated tables of "national" SUs were to be prepared, a modelling approach would be necessary to ensure consistency. Developing suitable models for Internet access is therefore required. These could be integrated with the national database under development by Meat NZ and Wools of NZ for sheep breeding (Geenty 1998). Model development will raise, again, the perennial issue of poorly defined input:output production functions for pastoral farms (Wragg 1970).

In order to identify the most profitable livestock system, farmers need to know the marginal change in profit associated with the options available. Since this depends on costs and prices, a financial model needs to be applied to the inputs and outputs from the biological model of livestock performance. Enterprise budgets (or gross margins) are usually adequate for this task. By constructing sensitivity tables, and assigning probabilities to the range of values used, the business risk associated with each option can also be estimated (Parker et al. 1998).

\section{Conclusions}

Livestock standards have been used in New Zealand in various ways for almost 80 years. However, the proliferation of their use in farming did not occur till the 1970s. Since that time, new standards have been derived, often in an ad hoc fashion and with limited empirical data, for a wider range of performance levels within stock classes and a greater diversity of farmed livestock species. The main misuse of the SU system has been in making between farm comparisons to identify "opportunities" for management action. Such comparisons may assist in the first stage of benchmarking by identifying farms with potentially superior management practice and technology use. The emphasis in benchmarking, however, is on farmers learning "best practice" rather than comparing their current performance with group or sector averages.

Computer models describing feed consumption by animal class within a whole farm system enable SU conversion factors, should they be necessary, to be derived for individual properties. Obtaining agreement on the specifications for these models is more important than agreeing on a national set of SUs, since the former provides a means of generating the latter. The Internet can make these generic models available to users in all sectors of agriculture. Integrating a financial model with the model of farm biology, allows the economic efficiency of farm systems to be estimated and the source(s) of greatest marginal gain to be identified. This will assist grassland farmers more than providing them with an agreed set of national SU standards.

\section{REFERENCES}

Amer, P.R.; McEwen, J.C. 1998. Breeding objectives for sheep. Occasional Publication, New Zealand Society in Animal Production (in preparation).

Anonymous. 1998. Northland study validates high MS trial. New Zealand Dairy Exporter 73(11): 14.

Atkinson, A.A.; Banker, R.D.; Kaplan, R.S.; Young, S.M. 1995. Management accounting. New York: Prentice-Hall International.

Baker, D.O. 1993. Background to the successful operation of the Wairarapa Farm Improvement Club, the system and benefits from the physical and financial database. Proceedings of the New Zealand Grassland Association 55: 11-16.

Blagburn, C.H. 1962. Farm standards and the theory of production economics - A rejoinder. Journal of agricultural economics 15(2): 291-295.

Brookes, I.M.; Morris, S.T.; Parker, W.J. 1993. Computer spreadsheets for predicting feed requirements and feed budgeting. Proceedings of the New Zealand Grassland Association 55: 209-210.

Candler, W.; Sargent, D.A. 1962. Farm standards and the theory of production economics. Journal of agricultural economics 15(2): 282-290.

Crawford, H.K.; Anderson, W.J. 1994. The use and misuse of the stock unit system. Proceedings of the 
New Zealand Society of Farm Management Conference (Flock House): 10-22.

Crawford, H.K.; Lowe, K.I. 1994. The stock unit system - fair treatment for the breeding cow? Proceedings of the New Zealand Society of Animal Production 54: 319-322.

Coop, I.E. 1965. A review of the ewe equivalent system. New Zealand agricultural science 1(3): 13-18.

Coop, I.E. 1967. The ewe equivalent system. The Canterbury Chamber of Commerce Bulletin, N. 454, Christchurch.

Cornforth, I.S.; Sinclair, A.G. 1984. Fertiliser and lime recommendations for pastures and crops in New Zealand. Wellington: Ministry of Agriculture and Fisheries.

Donaldson, T.H. 1987. Stock unit standardisation. Farm management news 48: 45-46.

Fawcett, E.J.; Paton, W.N. 1929. Livestock production. A review of livestock production in New Zealand during the past 26 seasons (1901/2 to 1926/27), based on standard values and units. pp. 990-1000. In: The New Zealand Year-Book (Vol. 37). Wellington: Government Printer.

Fleming, P.H.; Burtt, E.S. (eds.) 1991. Farm technical manual. Department of Farm \& Horticultural Management, Lincoln University.

Fitzharris, J. 1982. Comparison between the average and top farmers. Proceedings of the New Zealand Society of Farm Management Conference (Masterton): 51-57.

Garrick, D.G. 1994. The most profitable size of sheep. Breeding Matters, New Zealand Animal Breeding Trust, Massey University No. 5 (November).

Garrick, D.J.; Harris, B.L.; Johnson, D.L. 1997. The across-breed evaluation of dairy cattle in New Zealand. Proceedings of the Association for the Advancement of Animal Breeding Genetics (1): 611615.

Geenty, K.G. 1998. Improving national flock genetics. Wool Report, Wools of New Zealand, Wellington (March): p. 15.

Geenty, K.G. \& Rattray, P.V. 1987. The energy requirements of grazing sheep and cattle. pp. 3954. In: Livestock feeding on pasture, Nicol, A.M. (ed.) Occasional Publication No. 10, New Zealand Society of Animal Production.
Holmes, C.W. 1998. Personal communication. Institute of Veterinary, Animal \& Biomedical Sciences, Massey University.

Holmes, C.W.; Brookes, I.M.; Robertson, K. 1989. Symposium: Choice of breed for maximum productivity. Dairyfarming Annual 41: 15-23.

Hutton, J.B. 1954. Dairy farm survey of the Waipa County, 1940-41 to 1949-50. DSIR Research Bulletin 112. Wellington: New Zealand Department of Scientific \& Industrial Research,.

Jackson, R.H. 1963. Introduction. Proceedings of the New Zealand Institute of Agricultural Science: 115116.

Keeling, P.C.; Morris, S.T.; Gray, D.I.; Parker, W.J. 1991. A modelling study of once-bred heifer production. Proceedings of the New Zealand Society of Animal Production 51: 389-393.

King, M. 1982. The place of soil conservation on hill country. Proceedings of the New Zealand Society of Farm Management Conference (Masterton): 8590.

MAFPol 1994. National farm monitoring report. Wellington: MAF Policy.

Makeham, J.P.; Malcolm, L.R. 1993. The farming game now. Melbourne: Cambridge University Press.

Marshall, P.R.; McCall, D.G.; Johns, K.L. 1991. STOCKPOL: A decision support model for livestock farmers. Proceedings of the New Zealand Grassland Association 53: 137-140.

NZMWBES 1989. A review of current financial trends and farm incomes in the New Zealand sheep and beef industry. Paper G1996, New Zealand Meat \& Wool Board Economic Service, Wellington.

Parker, W.J; Dooley, A.E.; Garrick, D.G. 1998. Sheep breeding: An enterprise budgeting decision support model for on-farm planning. Proceedings of the New Zealand Society of Animal Production 58: 165169.

Romero-Garcia, J. 1998. Evaluating a new sheep breed on a hill country sheep farm. Unpublished MApplSc thesis, Massey University.

Shadbolt, N.M. 1997. Key performance indicators. Dairyfarming Annual 49: 107-111.

Wragg, S.R. 1970. Co-operative research and the provision of input-output coefficents. Journal of agricultural economics 13: 144-152. 